\title{
UM MODELO DIDÁTICO MISTO PARA A ARGUMENTAÇÃO NO ENSINO DE CIÊNCIAS E BIOLOGIA: PARA ALÉM DAS TENDENCIOSIDADES
}

\author{
A MIXED DIDACTIC MODEL TO THE ARGUMENTATION ON TEACHING \\ SCIENCES AND BIOLOGY: ABOVE THE TRENDS
}

\author{
Agnaldo Ronie Pezarini ${ }^{1}$ \\ ORCID iD: 0000-0001-7934-4399
}

Maria Delourdes Maciel $^{2}$

ORCID iD: $\underline{0000-0002-6821-5185}$

\begin{abstract}
RESUMO
Este artigo se refere aos resultados de uma pesquisa sobre a argumentação no ensino de Ciências e de Biologia. Sua singularidade está na construção de um Modelo Didático Misto (MDM), tendo como objetivo identificar se o MDM criado possibilita em alunos do nono ano do Ensino Fundamental e na terceira série do Ensino Médio a construção da argumentação de qualidade. Deve também verificar qual é o lugar e a relação entre explicação e narração com argumentação. Quanto à metodologia, a pesquisa é do tipo intervenção por intermédio de sequências didáticas, além da obtenção do diagnóstico inicial de concepção e habilidade argumentativa pela aplicação de questionário e obtenção de novas concepções, por meio da realização de um grupo focal pós-intervenção do MDM. Quanto aos resultados obtidos, esses foram relevantes tanto para a qualidade dos argumentos como das argumentações, pois houve um avanço de qualidade à medida que o MDM foi desenvolvido em suas fases e, quando analisadas as construções dos discentes, se constatou que houve avanço de qualidade estrutural e de conteúdo dos argumentos e das argumentações, uma vez que o nível de qualidade (NQA) nos alunos do

\footnotetext{
${ }^{1}$ Doutor em Ensino de Ciências e Matemática pela Universidade Cruzeiro do Sul - UNICSUL - (Conceito CAPES 6). Mestre em Educação pela Pontifícia Universidade Católica de Campinas. Possui Pós-graduação Lato sensu em Ensino de Ciências pela Universidade de São Paulo (USP) e Pós-graduação Lato sensu em Ética, Valores e Cidadania na Escola pela Universidade de São Paulo (USP); Possui Especialização em Atendimento a portadores de deficiência visual pela UFSCar; Graduação em Licenciatura Plena e Bacharelado em Ciências\&\#10;Biológicas Pontifícia Universidade Católica de Campinas (2001). Atualmente é Professor Efetivo - PEB II -Secretaria de Estado da Educação de São Paulo e Parecerista das revistas científicas REnCiMa, Dynamis e PEA. Tutor no Curso de Especialização em Ensino de Ciências Anos Finais do Ensino Fundamental, Ciência é 10! Pela UAB / Universidade Federal do ABC - UFABC. Endereço. Rua Victória Pareda Ferreira, 71 - Parque Cidade Campinas - Campinas/São Paulo - CEP 13069-051. E-mail: rpezarini@ gmail.com.

${ }^{2}$ Graduação em História Natural/Ciências Biológicas pela Universidade Federal do Rio Grande do Sul (1976); Mestrado em Educação (Supervisão e Currículo) pela Pontifícia Universidade Católica de São Paulo (1995); Doutorado em Educação (Psicologia da Educação) pela Pontifícia Universidade Católica de São Paulo (2001); Pós-doutorado em Educação: formação de professores pela Pontifícia Universidade Católica de São Paulo (2006). Professora Titular I - Quadro Permanente da Universidade Cruzeiro do Sul, onde atua como docente e pesquisadora na graduação e pós-graduação. Experiência profissional na área de Educação, com ênfase em Ensino de Ciências e Biologia, com os seguintes temas: Currículo, Ensino e Formação de Professores; Ensino de Ciências e Biologia; Didática e Metodologia de Ensino; Recursos Didáticos; Natureza da Ciência e da Tecnologia (NdC\&T)/Ciência, Tecnologia e Sociedade (CTS) no Currículo, no Ensino e na Formação de Professores. É representante brasileira na Diretoria da AIA-CTS (Associação Ibero-Americana Ciência-Tecnologia-Sociedade na Educação em Ciência); Coordenadora do NIEPCTS (Núcleo Interdisciplinar de Estudos e Pesquisas em CTS); Avaliadora ad hoc das Revistas IENCI (Investigações em Ensino de Ciências), Informática na Educação: teoria \& prática; Ciência \& Educação; Avaliadora ad hoc SINAES/MEC; Membro do Comitê de Ética em Pesquisa (CEP) e do Comitê de Ética em Uso de Animais (CEUA) da Universidade Cruzeiro do Sul; Coordenadora do NAPED-CBS da Universidade Cruzeiro do Sul. Rua: Galvão Bueno, 868, Bairro: Liberdade, São Paulo/São Paulo, Brasil, CEP: 01506-000. E-mail: delourdes.maciel@gmail.com.
} 
nono ano do Ensino Fundamental avançou do nível 1 para o nível 5 com a intervenção do MDM. Na terceira série do Ensino Médio, o NQA avançou de 2 para 5. A partir do MDM, também foi possível posicionar o lugar e identificar qual é a relação entre explicação e narração com argumentação. Contudo é possível afirmar que a argumentação é condição e possibilidade de qualidade para o ensino de Ciências e Biologia.

Palavras-chave: Argumentação. Ensino de Ciências e Biologia. Modelo Didático Misto. Toulmin. Bonini.

\begin{abstract}
This article refers to the results of a research about the argumentation in Teaching Sciences and Biology. Its singularity is in the building of the Mixed Teaching Model (MTM), setting as target to identify if the MTM created enables the students of nineth class of Fundamental School and the third class of High School to build quality argumentation and verify what is the place and the relation between the narrative and the argumentation. As regard to the methodology, the research is a kind of intervention thru didactic sequences, besides getting initial diagnosis of the conception and the argumentative skill by the application of a questionnaire and get new conceptions thru the performance of a focal group after the MTM intervention. As to the obtained results, they were relevant as to the quality of the arguments as well the argumentations, because there was an enhance in quality as the MTM was developed in its phases and, when analyzed the constructions of the students, it was noticed an enhance in the quality of the structure and arguments content and the argumentations once the quality level (AQL) in the nineth class of Fundamental School went from level 1 to level 5, with the intervention of the MTM. In third class of High School, the AQL went from level 2 to level 5. From the MTM, it was also possible to place and identify what is the relation between explanation and narrative with argumentation. However, it is possible to declare that the argumentation is condition and possibility of quality for the teaching of Sciences and Biology.
\end{abstract}

Keywords: Argumentation. Sciences and Biology Teaching. Mixed Teaching Model. Toulmin. Bonini.

\title{
1 INTRODUÇÃO
}

Nosso ponto de partida é o fato de que aprender Ciências se refere a uma ação de construção e avaliação de situações e fenômenos e, dessa forma, há evidentemente uma relação entre a construção desse conhecimento e a habilidade argumentativa. Diante de tal fato e da convicção de que a argumentação é condição para a construção do conhecimento científico, iniciamos a construção deste trabalho com a apresentação de seus objetivos, a saber: identificar se o MDM criado possibilita, em alunos do novo ano do Ensino Fundamental e naqueles da terceira série do Ensino Médio, a construção da argumentação de qualidade; saber qual é o lugar e a relação entre explicação e narração com a argumentação; além de seu questionamento norteador: por intermédio de um MDM, é possível construir argumentos e argumentações mais bem estruturados e de melhor qualidade? Desse modo, torna-se possível identificar nas argumentações construídas qual é o lugar e qual é a relação entre explicação e narração no processo de argumentação? 
Retomando a perspectiva de que a argumentação é parte essencial do processo de construção do conhecimento, recorremos a Jiménez-Aleixandre (2011), que enfatiza essa relação, descrita a seguir na Figura 1

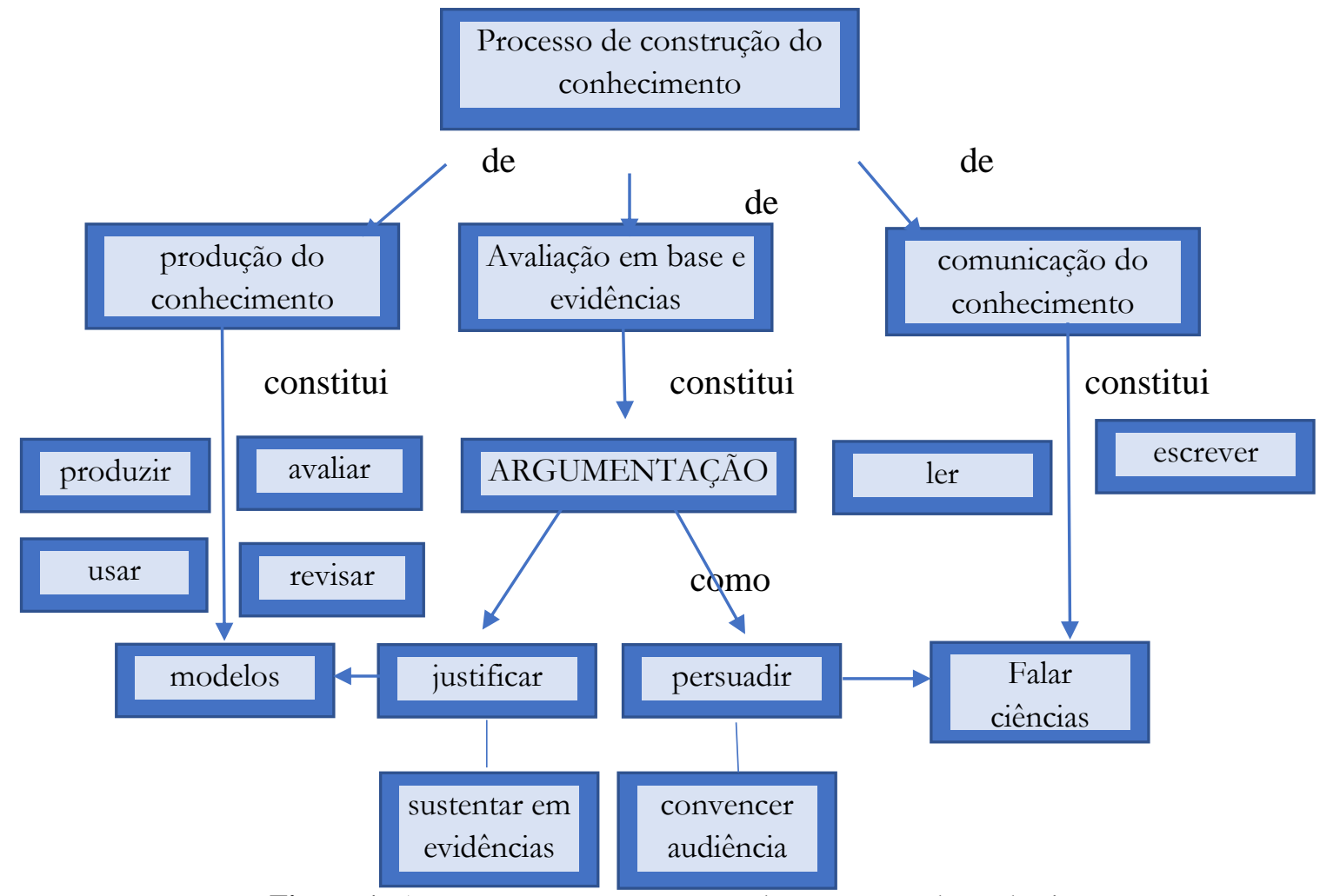

Figura 1: A argumentação no processo de construção do conhecimento. Fonte: JIMÉNEZ-ALEIXANDRE (2011, p. 142).

Dando ênfase à Figura 1, podemos afirmar que a argumentação e o ensino de Ciências e de Biologia interagem no processo de construção do conhecimento dessas áreas.

\section{REFERÊNCIAL TEÓRICO}

Para Van Eemeren e Grootendorst (2004, apud JIMÉNEZ-ALEIXANDRE; BROCOS, 2015, p. 142), a argumentação tem papel específico no processo de construção do conhecimento, pois "[...] o objetivo da argumentação é convencer um crítico razoável da aceitabilidade de um ponto de vista (persuasão), mediante a apresentação de proposições que justifiquem ou refutem o ponto de vista.".Diante dessa constatação, como proceder nas aulas de Ciências e Biologia? Driver, Newton e Osborne (2000) enfatizam que a prática argumentativa nas aulas de Ciências não deve ficar restrita apenas aos conteúdos, mas deve envolver também o exercício da cidadania. 
Assim, para além de se configurar como exercício da cidadania, o pensamento e o raciocínio devem ser significativos na vida da pessoa e é no argumento que nós podemos encontrar a maneira mais significativa de assim agir, como descreve Kuhn (1993, p. 322): "Pensamento como argumento está implicado em todas as crenças que as pessoas têm, nos julgamentos que elas fazem e nas conclusões que elas tiram.”.

No âmbito escolar, o desenvolvimento da habilidade argumentativa está para além da construção de uma habilidade, já que promove a possibilidade e a capacidade da exteriorização da aprendizagem de um conteúdo ensinado.

Contudo produzir argumentos científicos em sala de aula é uma possibilidade a partir da argumentação, ou seja, como descreve Motokane (2015, p. 128-129): “[...] quando os argumentos têm a chance de serem produzidos com base em argumentos científicos aprendidos em aula. Ao apresentarem seus argumentos, os alunos podem expressar como utilizam um determinado conceito científico para justificar uma opinião. Dessa forma, temos um indicador claro da aprendizagem do aluno.".

Quando as práticas em sala de aula se pautam na perspectiva da argumentação, a natureza social da atividade científica emerge com fluidez, uma vez que o aluno se torna apto a habilidades essenciais da prática científica, em especial da elaboração de explicações para situações problema e/ou fenômenos, como descrevem Ferraz e Sasseron (2017, p. 2):

[...] Devido à natureza social da atividade científica, a argumentação emerge como uma prática epistêmica central em seu desenvolvimento, pois envolve ações, como a elaboração de explicações sobre distintos fenômenos e, além disso, por meio da justificação de alegações e da concatenação de evidências teóricas e/ou empíricas, novas ideias são colocadas em debate para validação e aceitação pela comunidade.

Dialogar sobre a argumentação científica nos remete de imediato ao Padrão de Stephen Toulmin, que é a ferramenta de maior predominância nas pesquisas sobre argumentação no ensino de Ciências e de Biologia (MOTOKANE (2009); NASCIMENTO e VIEIRA (2011); PEZARINI e MACIEL (2018).

O Padrão de Toulmin (a seguir referido somente como PAT, 2006) é composto por seis elementos distintos que conduzem à construção dos argumentos e das argumentações. Em linhas gerais, demonstra a ação de estabelecer relação entre dados e conclusões a partir de uma evidência e a possibilidade de se refutar. Tais são as principais características do discurso com aspectos da argumentação científica.

O PAT foi assim descrido por Vieira e Nascimento (2008): é composto por seis elementos, sendo o primeiro uma conclusão (C), que pode ser confirmada por um dado (D), autorizado por uma lei de passagem $(\mathrm{G})$, que é retirada de uma base de apoio (A). A refutação 
(R) é a forma de invalidar essa passagem. Nesse processo, a conclusão é atenuada ou reforçada pelo qualificador (Q).

Retornando ao problema de pesquisa, constatamos que, em pesquisas a respeito de argumentação no Ensino de Ciências e Biologia (EC\&B), cabe responder qual é o lugar e a relação entre a argumentação com a explicação e a narração.

Uma possibilidade para responder a essa indagação está nas sequências narrativa e explicativa de Bonini (2007), as quais são categorizadas por esse autor como orientações discursivas. No que se refere à sequência narrativa, ela é certamente uma ação frutífera para esse tipo de discurso, enquanto a sequência explicativa está para além, porque pode sistematizar o conhecimento desenvolvido. Vale ressaltar que, tanto na sequência narrativa quanto na explicativa, o professor precisa atentar ao fato de que suas ações discursivas devem ser evocadas constantemente nesse processo, sendo ele sua parte engajadora e instigadora (VIEIRA, NASCIMENTO e MELO, 2015).

Quanto às especificidades das sequências narrativa e explicativa, podemos salientar que, na sequência narrativa de Bonini (2007), percebem-se cinco macroproposições, a saber: situação inicial, complicação, (re)ações, situação final e moral. Esse teórico (2007) ensina que os dois extremos da sequência se referem aos momentos de equilíbrio que se apresentam por meio de uma base descritiva, enquanto que os elementos centrais (complicação, re[ações] e resolução) são as situações que caracterizam a narração, uma vez que, nesses elementos, ocorre a quebra da ordem que desencadeia automaticamente uma reação, a qual leva a uma resolução e a um novo equilíbrio.

Cabe à moral a capacidade de reflexão complementar do fato narrado. Vislumbramos na sequência narrativa de Bonini (2007) uma ação frutífera para as aulas de Ciências no contexto da argumentação. Para além da simples ação de desenvolver as prerrogativas e as nuances da ação narrativa, esse modelo contribui para com outras sequências.

Na sequência explicativa de Bonini (2007), o objetivo é desenvolver uma resposta para a indagação: como? E, de maneira descritiva, responder a essa indagação envolve, de forma procedimental, responder a "como fazer para ...?”. Em linhas gerais, a sequência explicativa está composta por três fases, e não considera a fase inicial, por se tratar de uma preparação.

Ao apresentar essas três fases, busca-se um questionamento de modo a resolvê-lo ou respondê-lo detalhadamente, de tal modo que, quando se chega ao fim, torna-se possível sumarizar a resposta de forma a se avaliar o problema. A sequência explicativa de Bonini não está voltada apenas para a ação básica do ato de explicar, já que ela se apresenta composta de outras ações que viabilizam o processo de sistematização do conhecimento. 
Para o processo de construção de um MDM, é preciso retomarmos o PAT e atrelar a ele os resultados iniciais obtidos com a pesquisa. Esses resultados identificam que os discentes não são portadores da habilidade argumentativa e que, para além dessa carência, eles requerem condução para a construção de qualquer conhecimento científico. Em outras palavras, eles não possuem independência de pensamento e do raciocínio científico, realizando essa ação apenas a partir da condução. Com base na realidade apresentada, coube a indagação: como subsidiar os discentes de Ciências na condução do processo de construção de argumentos e argumentações, para que possam construir discursos argumentativos com qualidade e com evidências da relação entre explicação e narração com a argumentação? A indagação apresentada nos conduz à construção de um MDM que, segundo nossa concepção, possui relações e se faz propício e adequado diante do objetivo de sua construção. O referido MDM segue descrito na Figura 2.

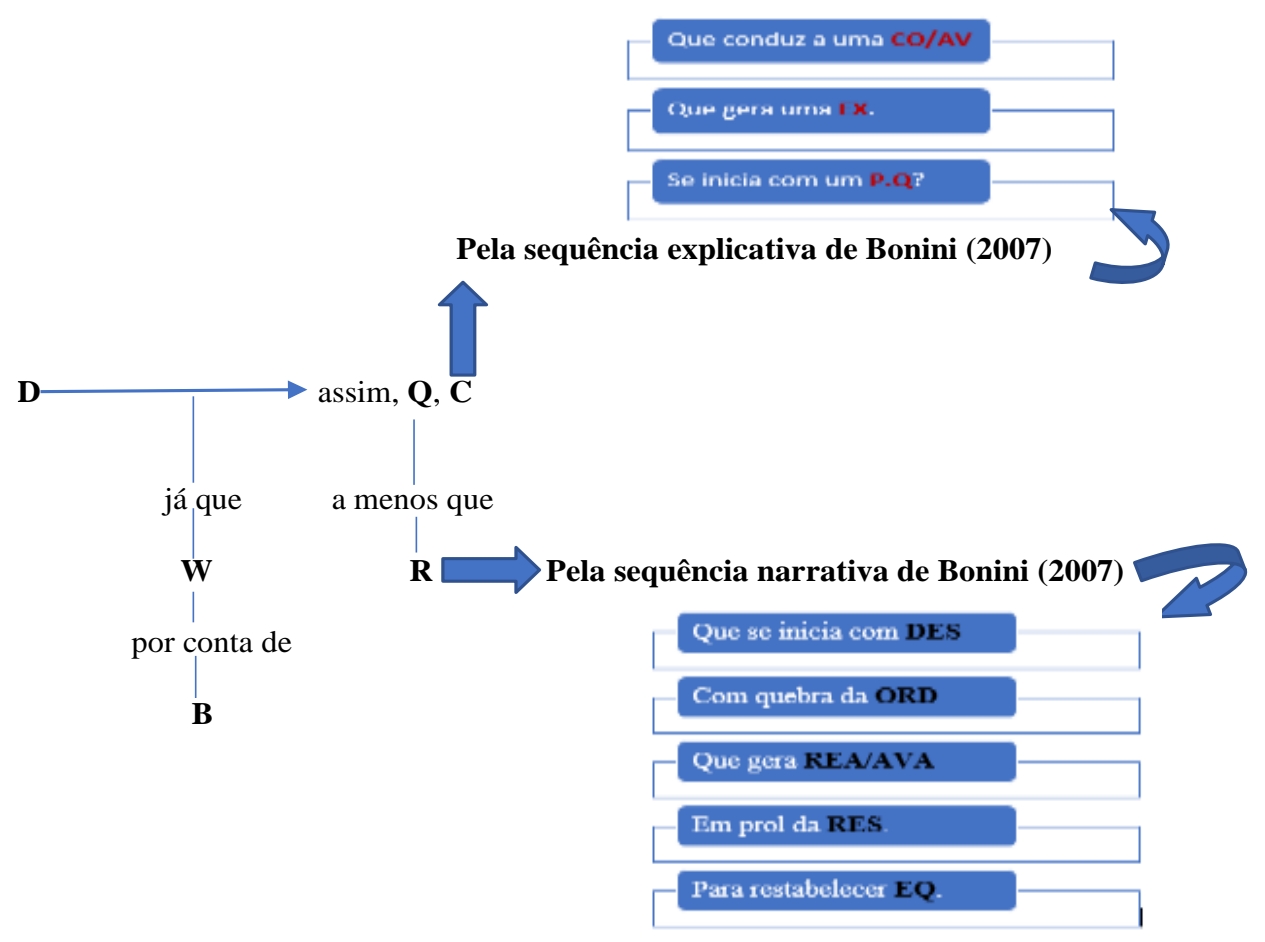

Figura 02: O Modelo Didático Misto.

Fonte: O autor. ${ }^{3}$

Tendo apresentado o MDM e seu desenvolvimento, é preciso destacar que sua

\footnotetext{
${ }^{3}$ Legenda: $\mathbf{D}=$ Dado $; \mathbf{Q}=$ Qualificadores modais $; \mathbf{C}=$ Conclusão; $\mathbf{W}=$ Garantia $; \mathbf{B}=$ Apoio $; \mathbf{R}=$ Refutação; PQ = a ação se inicia com um Por que?; $\mathbf{E X}=$ O Por quê? Promove uma explicação; CO/AV = gera uma conclusão/avaliação; DES = descrição inicial da refutação; ORD = de modo a quebrar a ordem estabelecida; REA/AVA = a quebra gera reações e avaliações; $\mathbf{R E S ~ = ~ e m ~ b u s c a ~ d a ~ r e s p o s t a ; ~} \mathbf{E Q}=$ para restabelecer o equilíbrio.
} 
construção está atrelada à ideologia e à parte do objetivo desta pesquisa, qual seja, o de identificar qual é o lugar e a relação entre a argumentação com a explicação e a narração. Desse modo, é possível afirmar que, com esse MDM, temos uma hipótese para a constatação de lugar e dessa relação. Contudo o nascedouro desse tem vistas à ratificação de que a argumentação no ensino de Ciências e de Biologia está fortemente relacionada às sequências narrativas e explicativas, sendo cada uma distinta em si, mas entrelaçadas e resultando em condição para a argumentação.

\section{METODOLOGIA}

Pensar nas questões metodológicas desta pesquisa nos remete de imediato ao objetivo de sua construção, qual seja o de identificar se o MDM criado possibilita em alunos do nono ano do Ensino Fundamental e naqueles da última série do Ensino Médio a construção de argumentação de qualidade e qual é o lugar e a relação entre explicação e narração com a argumentação.

Dessa forma, o processo metodológico desta pesquisa se iniciou com a aplicação de um questionário diagnóstico, aos participantes desta pesquisa, alunos do nono ano do Ensino Fundamental e da terceira série do Ensino Médio quanto à existência da habilidade argumentativa. Os resultados desses questionários foram analisados, à luz de Bardin (2006), em duas categorias que emergiram das respostas dos participantes, sendo elas: Categoria I - Análise do Antagonismo entre o que consta no Currículo Oficial do Estado de São Paulo e as afirmações dos participantes ao questionário; e Categoria II - o não desenvolvimento da habilidade argumentativa.

Após a constatação de que esses discentes/participantes eram desprovidos da habilidade argumentativa, demos continuidade à pesquisa do tipo intervenção que, por sua vez, foi subsidiada por Sequências Didáticas (SDs) construídas e aplicadas aos participantes.

Segundo Zabala (1998, p. 18), SDs são: “[...] um conjunto de atividades ordenadas, estruturadas e articuladas para a realização de certos objetivos educacionais, que têm um princípio e um fim conhecidos tanto pelos professores como pelos alunos.”. As SDs construídas são compostas por três fases distintas, a seguir expostas:

Fase I: construir o conhecimento científico específico sobre Sistema Nervoso (nono ano do Ensino Fundamental) e Sistema Endócrino (terceira série do Ensino Médio) e instigar os participantes à construção de argumentos e argumentações, sem quaisquer ações de 
interferência do docente pesquisador. Fase II: apropriação das especificidades do Padrão de Toulmin (2006) e reconstrução dos argumentos e das argumentações, a partir das mesmas situações problemas norteadores da Fase I, pautando-se no referencial citado. Fase III: construção do conhecimento das especificidades das sequências narrativa e explicativa de Bonini (2007) e apresentação do Modelo Didático Misto (MDM), produto da fusão entre o Padrão de Toulmin e as perspectivas de Bonini e da nova e atual reconstrução de argumentos e de argumentações, agora alicerçando suas ações ao MDM.

Após a intervenção, as produções/construções dos discentes participantes, tanto do nono ano do Ensino Fundamental quanto da terceira série do Ensino Médio, foram submetidas à análise quanto a sua qualidade e, para tanto, recorremos ao referencial de Penha (2012).

Para esse autor, a qualidade do argumento está relacionada a seu nível de complexidade, enquanto a qualidade das oposições está relacionada ao modo de oposições que se referem a contra-argumento e refutações. No que se refere à qualidade do conteúdo, essa se relaciona às justificativas do argumento diante dos aspectos de aceitabilidade e relevância, e daqueles de coerência e suficiência. Para a avaliação da qualidade do conteúdo das oposições, dois outros parâmetros são utilizados, sendo esses o grau de oposição da argumentação e a intensidade e o fluxo da argumentação.

Quanto à complexidade, os parâmetros - denominados de Níveis de Complexidade (C) de Penha (2012) - se pautam em um esquema proposto por Venville e Dawson (2010). Nesse caso, são quatro níveis de complexidade que se resumem na existência dos elementos que compõem o Padrão de Toulmin (Dado, Afirmações, Conclusões, Garantias, Justificativas, Qualificadores e Contra-argumentação ou Refutação).

Como mencionado, a qualidade do conteúdo dialoga com os aspectos específicos. Quanto a Aceitabilidade e Relevância (AR), Penha (2012, p. 124-125) esclarece que se trata da "Identificação da aceitabilidade e da relevância relacionada às razões que suportam a principal afirmação do argumento.”. Quanto à Coerência e Suficiência (CS), Penha (2012, p. 124-5) a expõe da seguinte forma:

[...] O argumento foi um todo coerente com cada um dos seus componentes desempenhando sua função estrutural, (dados dão evidências para suportar a justificação: garantias - explicitam a relação entre os dados e as conclusões; apoios explicitações que dão suporte as garantias, qualificadores - dão as condições nas quais as conclusões são verdadeiras contra afirmações - especificam as condições nas quais a afirmação não é válida além de serem suficientes para suportar as conclusões).

Para os itens Aceitabilidade e Relevância e Coerência e Suficiência, é atribuída uma pontuação de 0 a 2 . 
Quanto aos Níveis de qualidade do conteúdo das Oposições, para o critério de Grau de Oposição (GO), Penha (2012, p. 129-130) verifica e atribui pontuação de 0 a 3, a partir da existência de que "As oposições abordam e analisam diferentes aspectos das temáticas abordadas; trazem luz para novos aspectos; apresentam novas ideias; reafirmam ideias anteriores com outras justificações; analisam aspectos de coerência e incoerência entre as temáticas abordadas.". Paralelamente, para o critério Intensidade e Fluxo (IF) da Argumentação, o autor referenciado explica em sua análise que "As oposições são aceitáveis e relevantes e dão continuidade ao fluxo da argumentação.” e, da mesma forma, atribui pontuação de 0 a 3.

A classificação dos Níveis de Argumentação (NQA) ocorre pela relação entre a atribuição do nível de qualidade do argumento com o nível de qualidade da oposição, como descreve Penha (2012, p. 134):

[...] Nível 1: Baixa qualidade para ambos; Nível 2: Uma classificação de baixa qualidade e uma classificação de média qualidade; Nível 3: Média qualidade para ambos ou uma classificação de alta e uma classificação de baixa qualidade; Nível 4: Uma classificação de média qualidade e uma classificação de alta qualidade; Nível 5: Alta qualidade para ambos.

A obtenção dos referidos níveis de qualidade de (n) Número total de argumentos de Complexidade " $n$ " contidos no episódio; AR (n) Número total de argumentos contendo classificação "n” para Aceitabilidade e Relevância contidos no episódio; CS (n) Número total de argumentos contendo classificação " $n$ " de Coerência e Suficiência contidos no episódio; Número de Oposições contidas no episódio; CA Número de Contra-Argumentos contidos no episódio; R Número de Refutações contidas no episódio; GO (n) Número de Graus de Oposição " $n$ " contidos no episódio; IF (n) Número total de Intensidade e Fluxo "n" contido no episódio. Assim, a obtenção da Classificação obedece às seguintes condições segundo o Penha (2012, p. 135-6):

[...] Classificação Alta: C (1) $=0 \%$ e C (3) + C (4) $\geq \sim 40 \%$; AR (0) $=0 \%$, AR (2) $\geq$ $\sim 80 \%$; CS $(0)=0 \%, \mathrm{CS}(2) \geq \sim 80 \%$. O $\geq 3$ e CA $+\mathrm{R} \geq 3 ; \mathrm{GO}(3) \geq 0$ ou GO (3) $\geq 0$ GO (2) + GO (3) $\geq \sim 50 \%$; IF (0) = 0 e IF (2) + IF (3) $\geq \sim 80 \%$. Classificação Média: $\mathrm{C}(2)+\mathrm{C}(3) \geq \sim 50 \% ; \mathrm{AR}(2) \geq \sim 50 \%$; CS (2) $\geq \sim 50 \%$; O $\geq 3 ; \mathrm{e} \mathrm{CA}+\mathrm{R} \geq 3 ; \mathrm{GO}(1)$ $+\mathrm{GO}(2) \geq \sim 50 \%$; IF (2) + IF (3) $\geq \sim 50 \%$. Classificação Baixa: C (1) + C (2) $\geq \sim 50 \%$; $\mathrm{AR}(0)+\mathrm{AR}(1) \geq \sim 50 \% ; \mathrm{CS}(0)+\mathrm{CS}(1) \geq \sim 50 \% ; \mathrm{O} \geq 2$ e $\mathrm{CA}+\mathrm{R} \leq 2 ; \mathrm{GO}(0)+$ GO (1) $\geq \sim 50 \%$; IF (0) + IF (1) $\geq \sim 50 \%$.

Tendo obtido o NQA, prosseguimos com a pesquisa, realizando um Grupo Focal (GF) com cada ano/série dos participantes. As reuniões obedeceram a um roteiro que visava identificar e constatar qual era a nova ideologia e/ou a ressignificação de concepção e de 
aquisição da habilidade argumentativa após a pesquisa intervenção realizada. As respostas dos diálogos foram analisadas da mesma forma que o questionário, ou seja, pela análise de conteúdo de Bardin (2006) e essa análise ocorreu com as seguintes categorias: Categoria I: Ressignificação do conceito, da aprendizagem e da epistemologia dos professores; Categoria II: Aquisição e desenvolvimento do conhecimento argumentativo; Categoria III: Qualidade do ensino de Biologia e de Ciências pela argumentação: o pré e o pós pesquisa; e Categoria IV: Ação docente para a construção do conhecimento e da habilidade argumentativa.

A finalização da análise dos dados ocorreu com a triangulação dos dados das duas categorias de análise do questionário, com as quatro categorias de análise do GF, buscando, segundo Flick (2013), identificar e triangular os elementos de convergência, divergência e complementação.

\section{ANÁLISES E RESULTADOS}

A constatação dos resultados desta pesquisa, cujo objetivo é detectar a relevância e a eficiência do MDM, ocorre com a análise gradativa do NQA. Assim, compilamos a seguir as produções e as análises do NQA do Grupo de Trabalho (GT) V do nono ano do Ensino Fundamental e do GT IV da terceira série do Ensino Médio, para que sirvam de parâmetro e replicabilidade.

Nos Quadros 1, 2 e 3, a seguir, compilamos e realizamos a análise dos elementos de complexidade, bem como, os de qualidade do argumento com a aceitabilidade e relevância, assim como, para a qualidade das oposições em relação ao grau de oposição e Intensidade e Fluxo do nono ano. E, no Quadro 4, apresentamos a análise do NQA das produções deste GT. Nos Quadros 5, 6 e 7, os dados de análise se referem aos estudantes da terceira série do Ensino Médio. No Quadro 8, apresentamos a análise do NQA dos alunos da terceira série do Ensino Médio.

\begin{tabular}{|c|c|}
\hline Argumentação para a questão 01 & $\begin{array}{l}\text { Mapa da Qualidade da } \\
\text { Argumentação }\end{array}$ \\
\hline \multirow{3}{*}{$\begin{array}{l}\text { A propagação rápida do impulso nervoso é garantida pela } \\
\text { condução saltatória do impulso nervoso ao longo dos neurônios } \\
\text { isso pela presença da bainha de mielina que é lipídio e se faz } \\
\text { isolante elétrico para o impulso nervoso que é uma corrente } \\
\text { elétrica. }\end{array}$} & $\begin{array}{l}\text { Qualidade dos Argumentos } \\
C=2 / \mathrm{AR}=1 / \mathrm{CS}=1\end{array}$ \\
\hline & \begin{tabular}{|l|l|l|l|l|}
$\mathrm{D}$ & $\mathrm{W}$ & $\mathrm{C}$ & $\mathrm{Q}$ & $\mathrm{R}$ \\
\end{tabular} \\
\hline & $\begin{array}{l}\text { Qualidade das oposições } \\
\text { CA ou R = Não há oposição e/ou } \\
\text { refutação } \\
\text { GO = Não há oposição e/ou refutação } \\
\text { IF = Não há oposição e/ou refutação }\end{array}$ \\
\hline
\end{tabular}




\begin{tabular}{|c|c|}
\hline Argumentação para a questão 02 & $\begin{array}{l}\text { Mapa da Qualidade da } \\
\text { Argumentação }\end{array}$ \\
\hline & Qualidade dos Argumentos \\
\hline $\begin{array}{l}\mathrm{O} \text { álcool e as drogas, com o passar do tempo, podem danificar } \\
\text { uma parte do cérebro, mais especificamente dos neurônios. }\end{array}$ & $\begin{array}{l}C=1 / \mathrm{AR}=0 / \mathrm{CS}=1 \\
\begin{array}{|l|l|l|l|l|l|}\mathrm{D} & \mathrm{W} & \mathrm{C} & \mathrm{Q} & \mathrm{R} \\
\end{array}\end{array}$ \\
\hline & $\begin{array}{l}\text { Qualidade das oposições } \\
\text { CA ou R= Não há oposição e/ou } \\
\text { refutação } \\
\text { GO = Não há oposição e/ou refutação } \\
\mathrm{IF}=\text { Não há oposição e/ou refutação }\end{array}$ \\
\hline Argumentação para a questão 03 & $\begin{array}{l}\text { Mapa da Qualidade da } \\
\text { Argumentação }\end{array}$ \\
\hline $\begin{array}{l}\text { Nesse caso, há duas ações entre o Simpático e o Parassimpático. } \\
\text { Como ocorre quando o Sistema Simpático acelera os } \\
\text { batimentos cardíacos; e o parassimpático desacelera os } \\
\text { batimentos cardíacos. }\end{array}$ & $\begin{array}{l}\text { Qualidade dos Argumentos } \\
C=2 / \mathrm{AR}=1 / \mathrm{CS}=1 \\
\begin{array}{|l|l|l|l|l|}\mathrm{D} & \mathrm{W} & \mathrm{C} & \mathrm{Q} & \mathrm{R} \\
\text { Qualidade das oposições } \\
\text { CA ou } \mathrm{R}=\text { Não há oposição e/ou } \\
\text { refutação } \\
\mathrm{GO}=\text { Não há oposição e/ou refutação } \\
\mathrm{IF}=\text { Não há oposição e/ou refutação }\end{array}\end{array}$ \\
\hline
\end{tabular}

Quadro 1: Análise dos argumentos e das argumentações - GT V - Fase I.

Fonte: Quadro elaborado pelo autor.

\begin{tabular}{|c|c|}
\hline Argumentação para a questão 01 & $\begin{array}{l}\text { Mapa da Qualidade da } \\
\text { Argumentação }\end{array}$ \\
\hline $\begin{array}{l}\text { O impulso nervoso é extremamente veloz e se propaga } \\
\text { rapidamente por nossos neurônios por uma condução saltatória, }\end{array}$ & $\begin{array}{l}\text { Qualidade dos Argumentos } \\
C=4 / \mathrm{AR}=2 / \mathrm{CS}=2 \\
\begin{array}{|l|l|l|l|l|}\mathrm{D} & \mathrm{W} & \mathrm{C} & \mathrm{Q} & \mathrm{R} \\
\end{array}\end{array}$ \\
\hline $\begin{array}{l}\text { que ocorre devido ao efeito isolante da bainha de mielina, o } \\
\text { impulso segue saltando entre os Nós de Ranvier, fato que } \\
\text { acelera a propagação. }\end{array}$ & $\begin{array}{l}\text { Qualidade das oposições } \\
\text { CA ou R = Não há oposição e/ou } \\
\text { refutação } \\
\text { GO = Não há oposição e/ou refutação } \\
\text { IF = Não há oposição e/ou refutação }\end{array}$ \\
\hline Argumentação para a questão 02 & $\begin{array}{l}\text { Mapa da Qualidade da } \\
\text { Argumentação }\end{array}$ \\
\hline $\begin{array}{l}\text { O uso de álcool e drogas é prejudicial à sinapse. Eles anulam a } \\
\text { sinapse porque prejudicam ou anulam a ação dos } \\
\text { neurotransmissores, o que não permite ou torna lenta a } \\
\text { passagem do impulso de um neurônio para o outro e, nesse } \\
\text { caso, com o uso frequente e excessivo dessas substâncias, a } \\
\text { pessoa fica, como diríamos popularmente, "lesada". }\end{array}$ & $\begin{array}{l}\text { Qualidade dos Argumentos } \\
C=4 / \mathrm{AR}=2 / \mathrm{CS}=2 \\
\begin{array}{|l|l|l|l|l|}\mathrm{D} & \mathrm{W} & \mathrm{C} & \mathrm{Q} & \mathrm{R} \\
\text { Qualidade das oposições } \\
\text { CA ou } \mathrm{R}=\text { Não há oposição e/ou } \\
\text { refutação } \\
\text { GO = Não há oposição e/ou refutação } \\
\text { IF = Não há oposição e/ou refutação }\end{array}\end{array}$ \\
\hline Argumentação para a questão 03 & $\begin{array}{l}\text { Mapa da Qualidade da } \\
\text { Argumentação }\end{array}$ \\
\hline $\begin{array}{l}\text { O SNP autônomo age por antagonismo, porque um age } \\
\text { comandando a ação e o outro em desfazer a ação desempenhada }\end{array}$ & $\begin{array}{l}\text { Qualidade dos Argumentos } \\
C=3 / \mathrm{AR}=2 / \mathrm{CS}=2 \\
\begin{array}{|l|l|l|l|l|}\mathrm{D} & \mathrm{W} & \mathrm{C} & \mathrm{Q} & \mathrm{R} \\
\end{array}\end{array}$ \\
\hline $\begin{array}{l}\text { anteriormente. Como ocorre quando o simpático acelera os } \\
\text { batimentos cardíacos; e o parassimpático desacelera. }\end{array}$ & $\begin{array}{l}\text { Qualidade das oposições } \\
\text { CA ou R = Não há oposição e/ou } \\
\text { refutação } \\
\text { GO = Não há oposição e/ou refutação } \\
\text { IF = Não há oposição e/ou refutação }\end{array}$ \\
\hline
\end{tabular}

Quadro 2: Análise dos argumentos e das argumentações - Grupo de Trabalho V - Fase II.

Fonte: Quadro elaborado pelo autor. 


\begin{tabular}{|c|c|}
\hline Argumentação para a questão 01 & $\begin{array}{l}\text { Mapa da Qualidade da } \\
\text { Argumentação }\end{array}$ \\
\hline $\begin{array}{l}\text { A extrema velocidade do impulso nervoso é um fato. Mas como isso } \\
\text { ocorre? Isso acontece por causa da bainha de mielina que é composta de } \\
\text { lipídio, que bloqueia a propagação do impulso nervoso, com isso, o } \\
\text { impulso nervoso salta para onde não há bainha de mielina, resultando em } \\
\text { uma condução do tipo saltatória. Isso ocorre promovendo a rapidez, a } \\
\text { menos que uma pessoa tenha suas bainhas de mielina danificadas ou } \\
\text { então se ela for infelizmente usuária de álcool e drogas de maneira } \\
\text { acentuada, fato que desfaz a comunicação entre os neurônios. }\end{array}$ & $\begin{array}{l}\text { Qualidade dos Argumentos } \\
C=4 / \mathrm{AR}=2 / \mathrm{CS}=2 \\
\begin{array}{|l|l|l|l|l|}\mathrm{D} & \mathrm{W} & \mathrm{C} & \mathrm{Q} & \mathrm{R} \\
\text { Qualidade das oposições } \\
\text { CA ou R = Refutação } \\
\text { presente } \\
\mathrm{GO}=3 \\
\mathrm{IF}=2\end{array}\end{array}$ \\
\hline Argumentação para a questão 02 & $\begin{array}{l}\text { Mapa da Qualidade da } \\
\text { Argumentação }\end{array}$ \\
\hline $\begin{array}{l}\mathrm{O} \text { álcool e as drogas causam danos à sinapse. Mas como isso acontece? } \\
\mathrm{O} \text { uso contínuo de álcool e drogas danifica a comunicação entre os } \\
\text { neurônios, não havendo neurotransmissores, deixando a pessoa com seus } \\
\text { neurônios e sinapses lesadas, pois eles anulam os neurotransmissores. } \\
\text { Deve-se evitar o uso dessas substâncias para não danificar as sinapses e, } \\
\text { assim, não ficar lesado. Sendo assim, liberará neurotransmissores para a } \\
\text { construção da ponte de comunicação entre os neurônios. }\end{array}$ & $\begin{array}{l}\text { Qualidade dos Argumentos } \\
C=4 / \mathrm{AR}=2 / \mathrm{CS}=2 \\
\begin{array}{|l|l|l|l|l|}\mathrm{D} & \mathrm{W} & \mathrm{C} & \mathrm{Q} & \mathrm{R} \\
\text { Qualidade das oposições } \\
\text { CA ou R = Refutaçąo } \\
\text { presente } \\
\mathrm{GO}=3 \\
\mathrm{IF}=2\end{array}\end{array}$ \\
\hline Argumentação para a questão 03 & $\begin{array}{l}\text { Mapa da Qualidade da } \\
\text { Argumentação }\end{array}$ \\
\hline $\begin{array}{l}\text { Existe um antagonismo no Sistema Nervoso Periférico Autônomo. Qual } \\
\text { é esse antagonismo? Esse se deve ao fato de que o SNPA é dividido em } \\
\text { somático e autônomo com ações voluntárias e involuntárias. A ação da } \\
\text { porção involuntária requer que outra subdivisão exerça ação, no caso, o } \\
\text { simpático promove a ação e o seu parceiro, o parassimpático, desfaz a } \\
\text { ação. Isso não ocorre, a menos que o corpo não consiga realizar essas } \\
\text { ações involuntárias, precisando de aparelhos médicos. }\end{array}$ & $\begin{array}{l}\text { Qualidade dos Argumentos } \\
C=4 / \mathrm{AR}=2 / \mathrm{CS}=2 \\
\begin{array}{|l|l|l|l|l|}\mathrm{D} & \mathrm{W} & \mathrm{C} & \mathrm{Q} & \mathrm{R} \\
\text { Qualidade das oposições } \\
\text { CA ou R = Refutação } \\
\text { presente } \\
\mathrm{GO}=2 \\
\mathrm{IF}=2\end{array}\end{array}$ \\
\hline
\end{tabular}

Quadro 3: Análise dos argumentos e das argumentações Grupo de Trabalho V - Fase III. Fonte: Quadro elaborado pelo autor.

No Quadro 4, a seguir, descrevemos os resultados obtidos do GT V em cada uma das fases e identificamos qual é o NQA.

\begin{tabular}{|c|c|c|c|}
\hline \multicolumn{4}{|c|}{ Níveis de qualidade das argumentações do $9^{\circ}$ ano do Ensino Fundamental - Fase III } \\
\hline Descrição & FASE I & FASE II & FASE III \\
\hline Fases da pesquisa & I II III & I II IIII & I II III \\
\hline Complexidade (C) & $2-1-2$ & $4-4-3$ & $4-4-4$ \\
\hline Aceitabilidade e Relevância (AR) & $1-0-1$ & $2-2-2$ & $2-2-2$ \\
\hline Coerência e Suficiência (CS) & $1-1-1$ & $2-2-2$ & $2-2-2$ \\
\hline Contra-argumento (CA) - Refutação (R) & NH-NH- & NH-NH-NH & P-P-P \\
\hline Grau de oposição (GO) & NH-NH-NH & NH-NH-NH & $3-3-2$ \\
\hline Intensidade e Fluxo (IF) & NH-NH-I & NH-NH-NH & $3-3-2$ \\
\hline \multicolumn{4}{|c|}{ Síntese da análise dos níveis de qualidade - NQA } \\
\hline \multicolumn{4}{|c|}{$\begin{array}{l}\text { Legenda: } \mathrm{C} / \mathrm{P}=\text { Complexidade/Pontuação }-\mathrm{NH}=\text { Não houve }-\mathrm{P}=\text { Presente } \\
\text { OBS: Para cada questão, estão listadas as pontuações obtidas em cada uma das três fases para as três } \\
\text { questões. Logo, temos três colunas, uma para cada questão e, em cada coluna, três pontuações, sendo da } \\
\text { esquerda para a direita, fases Questão I, Questão: II e Questão: III. }\end{array}$} \\
\hline \multicolumn{4}{|c|}{$\begin{array}{l}\text { Fase I: Para a Complexidade do argumento, os resultados revelam que } 100 \% \text { das construções obtiveram } \\
\text { pontuação entre } 1 \text { e } 2 \text {, segundo o referencial C (1) + C (2) maior que 50\%, classificação baixa. Para AR, } \\
\text { obtivemos } 100 \% \text { das pontuações entre } 0 \text { e } 1 \text {, segundo o referencial AR (0) + AR (1) maior que } 50 \% \text {, }\end{array}$} \\
\hline
\end{tabular}


classificação baixa. Para CS, obtivemos $100 \%$ de pontuação 1 e, segundo o referencial se CS (0) + CS (1) maior que 50\%, a classificação é baixa. Como não obtivemos Oposição/Refutação, temos classificação baixa. Assim, Baixa para argumento e Baixa para Oposição, temos NQA nível 1.

Fase II: Para a Complexidade do argumento, os resultados revelam que $100 \%$ das construções obtiveram pontuação entre 3 e 4, segundo o referencial C (3) + C (4) maior que 40\%, classificação Alta. Para AR, obtivemos $100 \%$ das construções com pontuação 2, segundo o referencial AR (2) maior que $80 \%$, classificação Alta. Para CS, obtivemos $100 \%$ das construções com pontuação 2, segundo o referencial CS (2) maior que $80 \%$, a classificação é Alta. Como não houve Oposição/Refutação, temos uma classificação Baixa. Assim, classificação Alta para Argumento e Classificação Baixa para Oposição, NQA nível 3.

Fase III: Para a Complexidade do argumento, os resultados revelaram 100\% das construções com pontuação 4, segundo o referencial C (3) + C (4) maior que 40\%, classificação Alta. Para AR, obtivemos $100 \%$ das construções com pontuação 2, segundo o referencial AR (2) maior que $80 \%$, classificação Alta. Para CS, obtivemos 100\% das construções com pontuação 2, segundo o referencial CS (2) maior que $80 \%$, a classificação é Alta. Para essa fase, HOUVE Oposição/Refutação e, para o GO, 100\% das construções obtiveram pontuação 2 ou 3, segundo o referencial GO (2) + GO (3) maior que 50\%, classificação Alta. Para a IF, a pontuação das construções foi 100\% delas com pontuação entre 3 e 2 . Segundo o referencial IF (2) + IF (3) maior que 50\%, classificação Alta. Assim, temos uma classificação Alta para a Oposição/Refutação. Logo, Alta classificação para Argumento e Alta classificação para Oposição, NQA nível 5.

Avaliação por questão: Resumidamente, temos:

Questão 1: Classificação Média para o argumento; e Classificação Baixa para a Oposição = NQA 2.

Questão 2: Classificação Alta para o argumento; e Classificação Baixa para a Oposição = NQA 3

Questão 3: Classificação Alta para o argumento; e Classificação Alta para a Oposição = NQA 5.

Quadro 4: Níveis de qualidade das argumentações do nono ano - GT V nas três fases. Fonte: $\mathrm{O}$ autor.

Para o Ensino Médio, também compilamos as construções dos argumentos e das argumentações de um dos GT, nesse caso o GT IV para a terceira série do Ensino Médio, as quais seguem nos Quadros 5, 6 e 7. No Quadro 8, apresentamos a análise da obtenção do NQA.

\begin{tabular}{|c|c|}
\hline Argumentação para a questão 01 & Mapa da Qualidade da Argumentação \\
\hline $\begin{array}{l}\text { Como ela fez uma refeição com exagero de glicose } \\
\text { o pâncreas atuará produzindo o hormônio Insulina } \\
\text { que captura o excesso de glicose e guardará no } \\
\text { fígado. }\end{array}$ & $\begin{array}{l}\text { Qualidade dos Argumentos } \\
C=2 / \mathrm{AR}=2 / \mathrm{CS}=1 \\
\begin{array}{|l|l|l|l|l|}\mathrm{D} & \mathrm{W} & \mathrm{C} & \mathrm{Q} & \mathrm{R} \\
\text { Qualidade das oposições } \\
\text { CA ou R = Não há contra-argumento ou } \\
\text { refutação } \\
\text { GO = Não há contra-argumento ou refutação } \\
\text { IF = Não há contra-argumento ou refutação }\end{array}\end{array}$ \\
\hline Argumentação para a questão 02 & Mapa da Qualidade da Argumentação \\
\hline $\begin{array}{l}\text { O Tio Marcos tem Hipotireoidismo. Nesse caso, a } \\
\text { sua glândula tireoidea não produz ou produz } \\
\text { quantidade insuficiente dos hormônios T3 e T4. }\end{array}$ & $\begin{array}{l}\text { Qualidade dos Argumentos } \\
C=2 / \mathrm{AR}=2 / \mathrm{CS}=1 \\
\begin{array}{|l|l|l|l|l|}\mathrm{D} & \mathrm{W} & \mathrm{C} & \mathrm{Q} & \mathrm{R} \\
\end{array} \\
\text { Qualidade das oposições } \\
\text { CA ou R = Não há contra-argumento ou } \\
\text { refutação } \\
\text { GO = Não há contra-argumento ou refutação } \\
\text { IF = Não há contra-argumento ou refutação }\end{array}$ \\
\hline Argumentação para a questão 03 & Mapa da Qualidade da Argumentação \\
\hline $\begin{array}{l}\text { A pessoa portadora de diabetes tem problemas em } \\
\text { seu pâncreas, no sentido de que esse órgão tem } \\
\text { produção anormal de insulina o que gera um } \\
\text { acúmulo constante de glicose no sangue. }\end{array}$ & $\begin{array}{l}\text { Qualidade dos Argumentos } \\
C=3 / \mathrm{AR}=2 / \mathrm{CS}=2 \\
\begin{array}{|l|l|l|l|l|l|}\mathrm{D} & \mathrm{W} & \mathrm{C} & \mathrm{Q} & \mathrm{R} \\
\end{array} \\
\text { Qualidade das oposições }\end{array}$ \\
\hline
\end{tabular}




\begin{tabular}{|l|l|}
\hline & CA ou R = Não há contra-argumento ou \\
& refutação \\
& GO = Não há contra-argumento ou refutação \\
& IF = Não há contra-argumento ou refutação \\
\hline
\end{tabular}

Quadro 5: Análise dos argumentos e das argumentações - Terceira série B - GT IV - Fase I.

Fonte: Quadro elaborado pelo autor.

\begin{tabular}{|c|c|}
\hline Argumentação para a questão 01 & Mapa da Qualidade da Argumentação \\
\hline $\begin{array}{l}\text { Ana, após ter realizado uma refeição, como consta } \\
\text { descrito, teve o seu sistema endócrino acionado, no } \\
\text { sentido de que, pela geração de excesso de glicose, seu } \\
\text { pâncreas produzirá o hormônio Insulina que é o } \\
\text { responsável por capturar o excesso de glicose e guardá- } \\
\text { lo no fígado na forma de glicogênio para ser utilizada } \\
\text { em momentos de escassez de ingestão de glicose. }\end{array}$ & $\begin{array}{l}\text { Qualidade dos Argumentos } \\
C=3 / \mathrm{AR}=2 / \mathrm{CS}=2 \\
\begin{array}{|l|l|l|l|l|}\mathrm{D} & \mathrm{W} & \mathrm{C} & \mathrm{Q} & \mathrm{R} \\
\text { Qualidade das oposições } \\
\text { CA ou R = Refutação presente } \\
\text { GO = Não há contra-argumento ou refutação } \\
\mathrm{IF}=\text { Não há contra-argumento ou refutação }\end{array}\end{array}$ \\
\hline Argumentação para a questão 02 & Mapa da Qualidade da Argumentação \\
\hline $\begin{array}{l}\text { O Tio Marcos apresenta Hipotireoidismo, no caso os } \\
\text { sintomas apresentados de excesso de peso e dificuldade } \\
\text { em perder peso, sono em excesso são resultantes dessa } \\
\text { doença que ocorre em consequência de um metabolismo } \\
\text { lento em virtude da baixa produção de T3 e T4 por parte } \\
\text { da glândula Tireoide. }\end{array}$ & 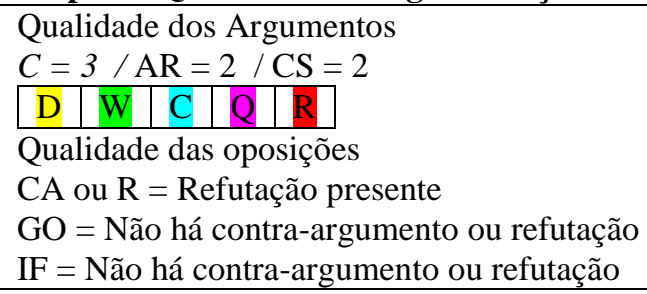 \\
\hline Argumentação p & Mapa da Qualidade da Argumentação \\
\hline $\begin{array}{l}\text { O Diabetes Melitus é uma doença caracterizada pela } \\
\text { elevação de glicose no sangue, isso pode ocorrer por } \\
\text { defeitos na secreção do hormônio insulina, que é } \\
\text { produzido pelas células beta do pâncreas. Neste caso, } \\
\text { como a principal função da insulina é promover a } \\
\text { entrada de glicose nas células, a ausência da insulina por } \\
\text { não produção do pâncreas, gera acúmulo de glicose no } \\
\text { sangue. }\end{array}$ & $\begin{array}{l}\text { Qualidade dos Argumentos } \\
C=3 / \mathrm{AR}=2 / \mathrm{CS}=2 \\
\begin{array}{|l|l|l|l|l|}\mathrm{D} & \mathrm{W} & \mathrm{C} & \mathrm{Q} & \mathrm{R} \\
\text { Qualidade das oposições }\end{array} \\
\text { CA ou } \mathrm{R}=\text { Refutação presente } \\
\text { GO = Não há contra-argumento ou refutação } \\
\mathrm{IF}=\text { Não há contra-argumento ou refutação }\end{array}$ \\
\hline
\end{tabular}

Quadro 6: Análise dos argumentos e das argumentações - Terceira série B - GT IV - Fase II.

Fonte: Quadro elaborado pelo autor.

\begin{tabular}{|c|c|}
\hline Argumentação para a questão 01 & $\begin{array}{l}\text { Mapa da Qualidade da } \\
\text { Argumentação }\end{array}$ \\
\hline $\begin{array}{l}\text { Uma alimentação com excessos gera problemas no nível de } \\
\text { glicose. Mas por que isso acontece? Quando temos glicose no } \\
\text { sangue, o pâncreas produz a insulina, que promove a entrada de } \\
\text { glicose nas células e captura o excesso de glicose no fígado, } \\
\text { promovendo o controle do nível de glicose normalmente, a menos } \\
\text { que a pessoa não tenha uma alimentação com excessos de glicose, } \\
\text { mas sim, uma alimentação balanceada que não gerará descontrole } \\
\text { de glicose no sangue. }\end{array}$ & $\begin{array}{l}\text { Qualidade dos Argumentos } \\
C=4 / \mathrm{AR}=2 / \mathrm{CS}=2 \\
\begin{array}{|l|l|l|l|l|}\mathrm{D} & \mathrm{W} & \mathrm{C} & \mathrm{Q} & \mathrm{R} \\
\text { Qualidade das oposições } \\
\text { CA ou R = Refutação presente } \\
\mathrm{GO}=2 \\
\mathrm{IF}=2\end{array}\end{array}$ \\
\hline Argumentação para a questão 02 & $\begin{array}{l}\text { Mapa da Qualidade da } \\
\text { Argumentação }\end{array}$ \\
\hline $\begin{array}{l}\text { O tio Marcos, ao que parece, é hipotireoideano. Mas como isso é } \\
\text { possível? Uma disfunção da glândula tireoide pode gerar vários } \\
\text { impactos ao corpo. Os sintomas apresentados pelo tio Marcos são } \\
\text { de hipotireoidismo, que acontece pelo baixo metabolismo, em } \\
\text { consequência da baixa produção dos hormônios da tireoide, o T3 }\end{array}$ & $\begin{array}{l}\text { Qualidade dos Argumentos } \\
C=4 / \mathrm{AR}=2 / \mathrm{CS}=2 \\
\begin{array}{|l|l|l|l|l|}\mathrm{D} & \mathrm{W} & \mathrm{C} & \mathrm{Q} & \mathrm{R} \\
\text { Qualidade das oposições }\end{array} \\
\text { CA ou R = Refutação presente }\end{array}$ \\
\hline
\end{tabular}




\begin{tabular}{|c|c|}
\hline $\begin{array}{l}\text { e o T4. Normalmente, a tireoide produz níveis normais e } \\
\text { suficientes desses hormônios, a menos que ela não esteja sendo } \\
\text { estimulada suficientemente pelo TSH que é o hormônio da } \\
\text { hipófise que a estimula. }\end{array}$ & $\begin{array}{l}\mathrm{GO}=3 \\
\mathrm{IF}=2\end{array}$ \\
\hline Argumentação para a questão 03 & $\begin{array}{l}\text { Mapa da Qualidade da } \\
\text { Argumentação }\end{array}$ \\
\hline $\begin{array}{l}\text { A pessoa diabética tem disfunção do pâncreas. Mas como essa } \\
\text { doença se constitui? O pâncreas produz o hormônio insulina, que } \\
\text { promove a entrada de glicose na célula, além de capturar o } \\
\text { excesso dela e guardar no fígado. Quando a pessoa tem disfunção } \\
\text { desse órgão/glândula, ela não tem insulina no organismo } \\
\text { acumulando glicose no sangue, neste caso, ela deverá tomar } \\
\text { medicação ou até mesmo injetar insulina várias vezes ao dia. Uma } \\
\text { doença que atualmente tem taxas elevadas de glicose. Essa doença } \\
\text { não aconteceria, se não houvesse disfunção do pâncreas e o nível } \\
\text { de insulina em seu corpo fosse constantemente nivelado. }\end{array}$ & $\begin{array}{l}\text { Qualidade dos Argumentos } \\
C=4 / \mathrm{AR}=2 / \mathrm{CS}=2 \\
\begin{array}{|l|l|l|l|l|}\mathrm{D} & \mathrm{W} & \mathrm{C} & \mathrm{Q} & \mathrm{R} \\
\\
\text { Qualidade das oposições } \\
\text { CA ou R= Refutação presente } \\
\mathrm{GO}=2 \\
\mathrm{IF}=2\end{array}\end{array}$ \\
\hline
\end{tabular}

Quadro 7: Análise dos argumentos e das argumentações - Terceira série B - GT IV - Fase III.

Fonte: Quadro elaborado pelo autor.

\begin{tabular}{|c|c|c|c|}
\hline \multicolumn{4}{|c|}{ Níveis de qualidade das argumentações do $9^{\circ}$ ano - Fase III } \\
\hline Descrição & FASE I & FASE II & FASE III \\
\hline Fases da pesquisa & & & \\
\hline Complexidade $(\mathrm{C})$ & $2-2-3$ & $3-3-3$ & $4-4-4$ \\
\hline Aceitabilidade e Relevância (AR) & $2-2-2$ & $2-2-2$ & $2-2-2$ \\
\hline Coerência e Suficiência (CS) & $1-1-2$ & $2-2-2$ & $2-2-2$ \\
\hline Contra-argumento (CA) - Refutação (R) & NH-NH- & NH-NH-I & P-P-P \\
\hline Grau de oposição (GO) & NH-NH- & NH-NH-N & $2-3-2$ \\
\hline Intensidade e Fluxo (IF) & NH-NH-I & NH-NH-N & $2-3-2$ \\
\hline \multicolumn{4}{|c|}{ Síntese da análise dos níveis de qualidade - NQA } \\
\hline \multicolumn{4}{|c|}{$\begin{array}{l}\text { Legenda: } \mathrm{C} / \mathrm{P}=\text { Complexidade/Pontuação }-\mathrm{NH}=\text { Não houve }-\mathrm{P}=\text { Presente } \\
\text { OBS: Para cada questão, estão listadas as pontuações obtidas em cada uma das três fases, para as três } \\
\text { questões. Logo, temos três colunas: uma para cada questão e, em cada coluna, três pontuações, sendo da } \\
\text { esquerda para a direita, fases Questão I, Questão II e Questão III. } \\
\text { Avaliação por Fase. }\end{array}$} \\
\hline \multicolumn{4}{|c|}{$\begin{array}{l}\text { Fase I: Para Complexidade do argumento, os resultados revelam pontuação } 2 \text { e } 3 \text { nas construções, } \\
\text { segundo o referencial C (2) + C (3) maior que } 50 \% \text {, classificação Média. Para AR, obtivemos } 100 \% \text { das } \\
\text { construções com pontuação } 2 \text {, segundo o referencial AR (2) maior que } 50 \% \text {, classificação Média. Para } \\
\text { CS, obtivemos } 75 \% \text { de pontuação } 1 \text { e } 25 \% \text { com pontuação } 2 \text {, segundo o referencial se CS (1) + CS (2) } \\
\text { maior que } 50 \% \text {, a classificação é Média. Como não obtivemos Oposição/Refutação, temos classificação } \\
\text { baixa. Assim, Média para argumento e Baixa para Oposição, temos NQA nível } 2 \text {. }\end{array}$} \\
\hline \multicolumn{4}{|c|}{$\begin{array}{l}\text { Fase II: Para a Complexidade do argumento, os resultados revelam que } 100 \% \text { das construções obtiveram } \\
\text { pontuação entre } 3 \text { e 4, segundo o referencial C (3) + C (4) maior que } 40 \% \text {, classificação Alta. Para AR, } \\
\text { obtivemos } 100 \% \text { das construçães com pontuação } 2 \text {, segundo o referencial AR (2) maior que } 80 \% \text {, a } \\
\text { classificação é Alta. Para CS, obtivemos } 100 \% \text { das construções com pontuação 2, segundo o referencial } \\
\text { CS (2) maior que } 80 \% \text {, a classificação é Alta. Como não houve Oposição/Refutação, temos uma } \\
\text { classificação Baixa. Assim, classificação Alta para Argumento e Classificação Baixa para Oposição, } \\
\text { NQA nível 3. }\end{array}$} \\
\hline \multicolumn{4}{|c|}{$\begin{array}{l}\text { Fase III: Para a Complexidade do argumento, os resultados revelaram } 100 \% \text { das construções com } \\
\text { pontuação } 4 \text {, segundo o referencial C (3) + C (4) maior que } 40 \% \text {, classificação Alta. Para AR, obtivemos } \\
100 \% \text { das construções com pontuação } 2 \text {, segundo o referencial AR (2) maior que } 80 \% \text {, classificação } \\
\text { Alta. Para CS, obtivemos } 100 \% \text { das construções com pontuação } 2 \text {, segundo o referencial CS (2) maior } \\
\text { que } 80 \% \text {, a classificação é Alta. Para essa fase, HOUVE Oposição/Refutação e, para o GO, } 100 \% \text { das } \\
\text { construções obtiveram pontuação } 2 \text { ou } 3 \text {, segundo o referencial GO (2) + GO (3) maior que } 50 \% \\
\text { classificação Alta. Para a IF, a pontuação das construções foi } 100 \% \text { delas com pontuação entre } 3 \text { e } 2 \text {. } \\
\text { Segundo o referencial IF (2) + IF (3), maior que 50\%, classificação Alta. Assim, temos uma classificação }\end{array}$} \\
\hline
\end{tabular}


Alta para a Oposição/Refutação. Logo, Alta classificação para Argumento e Alta classificação para Oposição, NQA nível 5.

Avaliação por questão: Resumidamente, temos:

Questão 1: Classificação Alta para o argumento; e Classificação Baixa para a Oposição = NQA 3

Questão 2: Classificação Alta para o argumento; e Classificação Baixa para a Oposição = NQA 3

Questão 3: Classificação Alta para o argumento; e Classificação Alta para a Oposição = NQA 5.

Quadro 8: Níveis de qualidade das argumentações do nono ano - GT V nas três fases.

Fonte: Construído pelo autor.

Graças a sequências didáticas analisadas, os quadros apresentados com os resultados obtidos da intervenção dialogam com o objetivo desta pesquisa, qual seja o de identificar se o MDM criado possibilita em alunos do nono ano do Ensino Fundamental e na terceira série do Ensino Médio a construção de argumentação de qualidade. Foi possível também verificar qual é o lugar e a relação entre a explicação e a narração com a argumentação, abrindo a discussão e a ponderação a respeito de tais resultados, uma vez que esses se mostraram relevantes para o contexto da educação e, mais especificamente, para a argumentação no EC\&B.

Após a análise dos argumentos e das argumentações dos estudantes do nono ano do Ensino Fundamental e da terceira série do Ensino Médio, em relação aos quesitos de qualidade estrutural (Complexidade, Aceitabilidade e Relevância, Coerência e Suficiência) e de conteúdo (Modos de oposição: grau de oposição e intensidade e fluxo), chegamos aos NQA que relevam, em um primeiro instante e sem as ações de intervenção, o NQA das construções - entenda-se aqui construção dos argumentos e das argumentações - o nível para alunos do nono ano do Ensino Fundamental era 1; e, para a terceira série do Ensino Médio, era 2.

Esse fato está em consonância com os resultados do questionário de diagnóstico, segundo o qual os estudantes declaram desconhecerem práticas de construção da argumentação em Ciências e em Biologia. Com a primeira intervenção, Fase II, que se refere à condução da construção de argumentos e argumentações por intermédio do Padrão de Toulmin, o NQA do nono ano do Ensino Fundamental foi igual a 3; e, para a terceira série do Ensino Médio, foi também igual a 3. Quando apresentamos e aplicamos o MDM, o NQA das construções dos estudantes, tanto para aqueles do nono ano do Ensino Fundamental, quanto para os alunos da terceira série do Ensino Médio foi igual a 5.

A constatação de que o NQA foi igual a 5 expressa a excelência da habilidade adquirida e, especificamente, expressa que o argumento e a argumentação foram coerentes, já que apresentaram os seis elementos específicos de uma argumentação para o EC\&B, sendo eles: dados, justificativa, garantias, conclusão, apoio e qualificadores.

Torna-se evidente a evolução do NQA após a intervenção do MDM. Entretanto o que de fato possibilitou e contribuiu para essa conquista e esses resultados? Inicialmente, podemos 
dizer que a ação e a postura do docente com vista ao objetivo da pesquisa foi um fator de contribuição, pois o processo de construção da argumentação requer uma prática de diálogo entre as partes envolvidas e, nesse caso, o docente/pesquisador atento a sua postura soube dar voz ao estudante e, de fato ser condutor do processo, já que o viés da argumentação está no ato de convencer o outro do seu ponto de vista e, ao que parece, quando os estudantes são conduzidos a construírem a conclusão de sua argumentação, pautando-se na sequência explicativa e na sua refutação na sequência narrativa, ele recebeu subsídios para que essa ação fosse concluída.

É possível dizer também que, quando o docente conduz o processo, ele faz emergir pensamento como argumentos em um processo de discurso efetivo, dotado de persuasão quanto aos pontos de vista. Para o EC\&B, sua condução por meio do viés da argumentação permite ao aluno que ele se expresse de modo a fazer uso de um determinado conhecimento de caráter científico para justificar o seu ponto de vista.

A partir dos resultados alcançados em nossa pesquisa, podemos considerar que o MDM se configura como uma nova prática pedagógica, cujo elemento válido e essencial é o fato de permitir interação entre docente e alunos e entre alunos em comparação com outros alunos. Tal fato é o resultado do que verificamos nas turmas em que foi aplicada a construção de uma nova cultura do pensar Ciências e Biologia. Ademais, os alunos do nono ano do Ensino Fundamental e os da terceira série do Ensino Médio participantes desta pesquisa criaram uma nova forma de se posicionarem, a fim de tomarem decisões diante dos acontecimentos. O MDM é, portanto, capaz de conduzir estudantes a uma ação efetiva, na qual eles são os protagonistas do conhecimento, já que esse modelo apenas os conduz à construção de saberes e conhecimentos de natureza científica.

Outro aspecto a ser considerado é que o MDM promoveu a melhoria no ensino de Ciências e de Biologia, fato esse que está em consonância com o que descreve Souza et al. (2018), quando afirmam que a melhoria da qualidade do aprendizado só é possível quando todos os envolvidos - professores e alunos - atuem com efetiva participação e que essa melhoria resulte em algo para além, que se refere ao Letramento Científico.

\section{CONSIDERAÇÕES}

A necessidade de que as práticas educativas nas aulas de Ciências sejam pautadas na competência argumentativa é uma afirmação compartilhada por grande parcela dos docentes dessa disciplina. No entanto essa não é uma realidade vivenciada no âmbito escolar, seja pela 
carência na formação docente, seja pelos imperativos que impossibilitam tal prática, como é o caso da existência de um currículo engessado. Conduzir os alunos a um processo de construção do pensamento científico é um dos pilares da argumentação, uma vez que pensamento e linguagem estão intimamente relacionados.

Enaltecemos a importância deste trabalho, especialmente quanto às contribuições que trazem para o ensino de Ciências e de Biologia. Tais contribuições resultam na capacidade da construção do pensamento crítico, de se posicionar e promover discussões fundamentadas, dado o fato de que a argumentação confere condições para tal. Em outras palavras, com este trabalho, fica evidente que o docente é o condutor do processo de construção atrelada a sua postura de dar a palavra a todos no processo de construção do conhecimento e, a partir daí, com discussões pautadas em referenciais, se posicionar e defender a sua percepção e ideologia diante das problemáticas e dos fenômenos da ciência e do seu entorno.

Outra contribuição evidente que os resultados desta pesquisa trazem é a de que o MDM se mostra uma estratégia pedagógica eficaz para a construção da argumentação que dá subsídios para a construção do pensamento crítico, pois ter a habilidade de pensar criticamente se torna possível graças à argumentação.

\section{REFERÊNCIAS}

JÍMENEZ-ALEIXANDRE, M. P. Argumentación y uso de las pruebas: Construcción, evaluación y comunicación de explicaciones en Biología y Geología. In: Didáctica de la biologia y la geologia (p. 129-150). Secretaría General Técnica. 2011. Disponível em: https://dialnet.unirioja.es/servlet/articulo?codigo=3659233. Acesso em 20 jul. 2020.

BARDIN, L. Análise de conteúdo. Lisboa: Edições 70, 2006, 225p.

BONINI, A. A noção de sequência textual na análise pragmático-textual de Jean-Michel Adam. Gêneros: teorias, métodos, debates. São Paulo: Parábola Editorial, 2007, p. 208-236.

DRIVER, R.; NEWTON, P.; OSBORNE, J. Establishing the norms of scientific argumentation in classrooms. Science education, 84 (3), 2000, p. 287-312. Disponível em: https://onlinelibrary.wiley.com/doi/abs/10.1002/(SICI)1098-37X(200005)84:3\%3C287::AIDSCE1\%3E3.0.CO;2-A. Acesso em 20 jul. 2020. DOI: https://doi.org/10.1002/(SICI)1098237X(200005)84:3<287::AID-SCE1>3.0.CO;2-A.

FERRAZ, A. T.; SASSERON, L. H. Propósitos Epistêmicos para a Promoção da Argumentação em Aulas Investigativas. Investigações em ensino de ciências, 22 (1). 2017. Disponível em: https://pdfs.semanticscholar.org/b622/c0380dda3856b314fc70349b1232ad35fa11.pdf. Acesso em 21 jul. 2020. DOI: http://dx.doi.org/10.22600/1518-8795.ienci2017v22n1p4.2.

FLICK, U. Introdução à metodologia de pesquisa. Porto Alegre: Penso, 2009. 
JIMÉNEZ-ALEIXANDRE, M. P.; BROCOS, P. Desafíos metodológicos en la investigación de la argumentación en la enseñanza de las ciencias. Ensaio Pesquisa em Educação em Ciências (Belo Horizonte, MG), 17 (spe), 2015, p. 139-159. Disponível em: https://www.scielo.br/pdf/epec/v17nspe/1983-2117-epec-17-0s-00139.pdf. Acesso em 20 jun. 2020. DOI: https://doi.org/10.1590/1983-2117201517s08.

KUHN, D. Ciência como argumento: implicações para o ensino e aprendizagem do pensamento científico. Science Education, 1993, v. 77 (3), 319-337. Disponível em: https://psycnet.apa.org/record/1993-43207-001 . Acesso em 19 set. 2020. Doi: https://DOI.org/10.1002/sce.3730770306

MOTOKANE, T. M.; GUELERO, M. Análise da argumentação presente em textos escritos de genética. Enseñanza de las ciencias: Revista de Investigación y Experiencias Didácticas, [em línea], 2009, n. ${ }^{\circ}$ Extra, p. 547-50. Disponível em: https://www.raco.cat/index.php/Ensenanza/article/view/293593. Acesso em 18 Jun. 2020.

MOTOKANE, M. T. Secuencias Didácticas Investigativas y Argumentación en la Enseñanza de la Ecología. Ensaio Pesquisa em Educação em Ciências (Belo Horizonte, MG), 17 (spe), 2015, p. 115-138.

MOTTA, M. B.; LIRA, M. R. A tessitura do discurso argumentativo numa sala de aula de ciências. Enseñanza de las ciencias: Revista de Investigación y Experiencias Didácticas, (Extra), 2013, p. 276-279. Disponível em: https://www.scielo.br/scielo.php?pid=S1983$21172015000400115 \&$ script=sci_abstract\&tlng=es. Acesso em 18 jun. 2020. DOI: https://doi.org/10.1590/1983-2117201517s07.

NASCIMENTO, S. S.; VIEIRA, R. D. Contribuições e limites do padrão de Argumento de Toulmin aplicado em situações argumentativas de sala de aula de ciências. Revista Brasileira de Pesquisa em Educação em Ciências, 8 (2). 2011. Disponível em: https://periodicos.ufmg.br/index.php/rbpec/article/view/4018/2582. Acesso em 17 jun. 2020.

PENHA, S. P. D. Atividades Sociocientíficas em sala de aula de Física: As argumentações dos estudantes (Tese Doutorado), Universidade de São Paulo, 2012.

PENHA, S. P.; CARVALHO, A. M. P. Proposição de uma Ferramenta Analítica para avaliar a Qualidade da Argumentação em Questões Sociocientíficas. Anais. ENPEC, Universidade Federal de Santa Catarina, Florianópolis, SC, 2015.

PERELMAN, C.; OLBRECHTS-TYTECA, L.; COELHO, F. O. Tratado da argumentação: A nova retórica. São Paulo: Martins Fontes. 2005.

PEZARINI, A. R.; MACIEL, M. D. As dimensões da argumentação no ensino de ciências em pesquisas de 2007 a 2017: Um olhar para a caracterização e para as ferramentas metodológicas para estudar esta temática. Amazônia: Revista de Educação em Ciências e Matemáticas, 14 (32), 2018, p. 61-77. Disponível em: https://periodicos.ufpa.br/index.php/revistaamazonia/article/view/6177/5267. Acesso em 15 jun. 2020.

SOUZA, T. T. de; HENCKES, S. B. R.; GEWEHR, D.; SCARTEZZINI, B.; STROHSCHOEN, A. A. G. Letramento científico na docência de professores de biologia: concepção e 
prática. REAMEC - Rede Amazônica de Educação em Ciências e Matemática, [S.1.], v. 6, n. 2, p. 310-323, 2018.DOI: 10.26571/REAMEC.a2018.v6.n2.p310-323.i6560. Disponível em: https://periodicoscientificos.ufmt.br/ojs/index.php/reamec/article/view/6560. Acesso em: 21 set. 2020.

TOULMIN, S. E. Os usos do argumento. $2^{\text {a }}$ edição. São Paulo: Martins Fontes, 2006.

VENVILLE, G. J.; DAWSON, V. M. The impact of a classroom intervention on grade 10 students' argumentation skills, informal reasoning, and conceptual understanding of science. Journal of Research in Science Teaching, 47 (8), 2010, p. 952-977. Disponível em: https://onlinelibrary.wiley.com/doi/abs/10.1002/tea.20358. Acesso em 18 jun. 2020. DOI: https://doi.org/10.1002/tea.20358.

VIEIRA, R. D.; NASCIMENTO, S. D. Avaliações de argumentação de licenciandos em Física sobre um episódio de estágio curricular: Em que critérios eles se baseiam. Anais EPEF, XI, 2008, p. 01-12.

VIEIRA, R. D.; NASCIMENTO, S. S.; MELO, V. F.; DA ROCHA BERNARDO, J. R. Argumentação e orientações discursivas na educação em ciências. Ensaio Pesquisa em Educação em Ciências, 17 (3), 2015, p. 707-725. Disponível em: https://www.scielo.br/pdf/epec/v17n3/1983-2117-epec-17-03-00707.pdf. Acesso em 16 jun. 2020. Doi: https://doi.org/10.1590/1983-21172015170308

ZABALA, A. A prática educativa: Como ensinar. Porto Alegre: Penso Editora, 2015.

Submetido em: 13 de julho de 2020.

Aprovado em: 08 de setembro de 2020 . 